\title{
Laparoscopic D1 + Lymph Node Dissection for Gastric Cancer in Jehovah's Witness Patients: a 1:3 Matched Case Control Study
}

\author{
Ji Keun Lee, M.D. ${ }^{1}$, Yong Jin Kim, M.D., Ph.D. ${ }^{1}$, Suyeon Park, M.S. ${ }^{2}$ \\ Departments of 'Surgery and 'Biostatistics, Soonchunhyang University Hospital, Seoul, Korea
}

Purpose: Laparoscopic gastrectomy in early gastric cancer patients is accepted as standard, but it is sometimes challenging for patients who refuse blood transfusions such as Jehovah's Witness (JW) patients, because of the risk of bleeding related to radical lymph node dissection. This study aimed to confirm the adequacy and safety of laparoscopic gastrectomy with D1+ lymphadenectomy in JW patients.

Methods: From January 2009 to December 2015, 265 gastric cancer patients underwent laparoscopic gastrectomy in our institute. Among them, there were $25 \mathrm{JW}$, and they were statistically matched with 75 patients from the control groups depending on age, sex, and body mass index (BMI). In a retrospective review, patient laboratory values and their pathology results were analysed.

Results: There was no significant difference when comparing the clinical characteristics of JW and control groups. There was no statistically significant difference in blood loss or operation time between the two groups. Mean blood loss was $202.4 \pm 172.6 \mathrm{ml}$ in the JW group and $179.7 \pm 163.8 \mathrm{ml}$ in the control group ( $p=0.556$ ). The number of retrieved lymph nodes was $27.8 \pm 13.9$ in the JW group and $29.3 \pm 12.1$ in the control group $(p=0.607)$. Haemoglobin and haematocrit were measured after surgery and there was no statistically significant difference between the two groups.

Conclusion: Laparoscopic D1+ gastrectomy in a JW may be performed with an equivalent risk to the control group. Laparoscopic gastrectomy can be applied to Jehovah's Witnesses if the specialied cancer center has sufficient experience in stomach cancer surgery, even if there is not enough experience in bloodless surgery.

Keywords: Jehovah’s Witness, Laparoscopic gastrectomy, D1+ lymphadenectomy
Received August 16, 2017

Revised September 7, 2017

Accepted September 20, 2017

Corresponding author

Yong Jin Kim

Department of Surgery, Soonchun-

hyang University Hospital, Hannam-

dong, Yongsan-gu, Seoul 04401,

Korea

Tel: $+82-2-710-3080$

Fax: +82-2-749-0449

E-mail: yjgs1997@gmail.com
This is an Open Access article distributed under the terms of the Creative Commons Attribution Non-Commercial License (http:// creativecommons.org/licenses/by-nc/4.0/) which permits unrestricted non-commercial use, distribution, and reproduction in any medium, provided the original work is properly cited.
Copyright $\odot 2017$ The Journal of Minimally Invasive Surgery. All rights reserved.

\section{INTRODUCTION}

After Kitano et al. reported on laparoscopic gastrectomy in 1994, this approach as become widely accepted as a standard procedure of surgical treatment in Korea and Japan., ${ }^{1,2}$ Clinical studies are underway to expand the application of laparoscopic gastrectomy to advanced gastric cancer, although whose oncological safety has not been proven. ${ }^{3}$

The most important part of the laparoscopic approach in advanced gastric cancer is D2 lymphadenectomy, which is accepted as a standard treatment. Laparoscopic D2 lymphadenectomy is known to be technically easy and safe, but it is also associated with the risk of bleeding and the subsequent need for blood transfusion. ${ }^{4}$

In the case of Jehovah's Witnesses, who refuse blood transfusions for religious reasons, laparoscopic radical lymphadenectomy is especially challenging. Laparoscopic D1+ lymphadenectomy has been performed on Jehovah's Witnesses with 
gastric cancer since 2009 at our institution. This study was conducted to evaluate the adequacy and safety of laparoscopic surgery for gastric cancer, including D1+ lymphadenectomy in Jehovah's Witnesses.

\section{MATERIALS AND METHODS}

\section{Patient selection and data collection}

A total of 265 patients, who underwent laparoscopic surgery for gastric cancer at our hospital, Seoul from January, 2009 to December, 2015, were enrolled in this study. The Jehovah's Witness (JW) group consisted of 25 participants, and the control group, of 240 participants. Seventy-five patients were selected for comparison with the JW group through propensity score matching (PSM) based on age, sex, and body mass index (BMI). The "MatchIt" package and $\mathrm{R}$ version 3.1.2 program were used for statistical analysis.

The following preoperative data were examined: history of blood transfusion, age, height, weight, sex, preoperative haemoglobin, haematocrit, RBC count, iron use, and accompanying diseases. Intraoperative data such as estimated blood loss, operation time, history of blood transfusion and autologous blood transfusion, method of anastomosis, and the range of lymphadenectomy were reviewed from the surgical database. Postoperative laboratory values, the number of LNs obtained from the operation, pathologic staging, hospitalization period, postoperative complications and reoperation were also investigated

This study was approved by the ethics committee/institutional review board (IRB no. 2017-07-021-001) of our medical center.

\section{Informed consent}

Prior to all the surgeries, the doctors and anaesthesiologists discussed the risk of refusing blood transfusion. If necessary, they also discussed about the use of iron supplements and hematopoietics before surgery, and the use of acute normovolemic haemodilution (ANH). Through these discussions, patients were informed about the risk of not receiving blood transfusions, and signed their consent forms at their discretion. The consent form consisted of several parts, pertaining to each step of the surgical procedure from whole blood transfusion to component transfusion. Patients could also decide whether to use hematopoietics and iron supplements.

\section{Operation method}

Surgery was performed by a single surgeon. Five ports were used during surgery and an additional trocar was used occasionally at the sub xiphoidal area $(5 \mathrm{~mm}$, for the liver retractor) according to the size of patient's liver. The operative procedure was standardized with performance of partial omentectomy and D1+ or over lymphadenectomy based on the guidelines of the Japanese Research Society for Gastric Cancer. For lymphadenectomy, advanced bipolar (LigaSure ${ }^{\mathrm{TM}}$ Maryland jaw, Medtronic, Minneapolis, MN, USA) and monopolar Bovie instrument (Suction-Hook Bovies, Endopath Probe, Ethicon, USA) were used. No commercially available haemostatic agents were used in this procedure.

\section{Statistical analysis}

The statistical analysis was performed using the SPSS $^{\odot}$ Sta- $^{-}$ tistics for windows version 18.0 ( $\mathrm{IBM}^{\odot}$ Corp., Armonk, NY, USA) for data analysis. Data was summarized using range, mean, standard deviation and median (with its 95\% confidence interval) with interquartile range (IQR) for quantitative variables, and frequency and percentage for qualitative ones. Comparison between groups was performed using the Mann Whitney test for quantitative variables and Chi square with Fisher's exact test for qualitative ones. The $p$ values less than 0.05 were considered statistically significant.

\section{RESULTS}

\section{Patient characteristics}

With regards to age, sex, BMI, co-morbidities, and ASA score, patient characteristics were well distributed between JW group $(\mathrm{N}=25)$ and control group $(\mathrm{N}=75)$. The mean age and the

Table 1. Clinical characteristics

\begin{tabular}{|lccc|}
\hline & $\begin{array}{c}\text { Control } \\
(\mathbf{n}=75)\end{array}$ & $\begin{array}{c}\text { Jehovah's } \\
\text { Witnesses }(\mathbf{n}=25)\end{array}$ & $p$ value \\
\hline Age, years & $58.5 \pm 14.5$ & $57.5 \pm 13.5$ & 0.759 \\
\hline Sex & & & 1.000 \\
Male & $27(36 \%)$ & $9(36 \%)$ & \\
Female & $48(64 \%)$ & $16(64 \%)$ & \\
\hline BMI, kg/m ${ }^{2}$ & $23.5 \pm 3.65$ & $23,6 \pm 3.51$ & 0.956 \\
\hline Co-morbidities & $42(56 \%)$ & $13(52 \%)$ & 0.818 \\
\hline ASA score & & & 1.000 \\
1 & $34(45.3 \%)$ & $15(60 \%)$ & \\
2 & $36(48 \%)$ & $9(36 \%)$ & \\
3 & $5(6.7 \%)$ & $1(4 \%)$ & \\
\hline
\end{tabular}


mean BMI of the 25 patients in the JW group was 57.5 (range: 27 76) years, and 23.6 (range: 17.2 30.6) $\mathrm{kg} / \mathrm{m}^{2}$, respectively.

The percentage of men in the JW group was $36 \%$. There was no statistically significant difference in the frequency of $\mathrm{co}^{-}$ morbidities and the ASA score between the JW and control groups (Table 1).

\section{Perioperative outcomes (Table 2)}

There was no difference between the JW and control groups in terms of gastric resection margins, combined resections, mean blood loss, retrieved lymph nodes and operation time. Mean blood loss was $202.4 \pm 172.6 \mathrm{ml}$ in the JW group and $179.7 \pm 163.8 \mathrm{ml}$ in the control group ( $p$ value $=0.556$ ). The number of retrieved lymph nodes was $27.8 \pm 13.9$ in the JW group and $29.3 \pm 12.1$ in the control group ( $p$ value $=0.607$ ). The operation time was $212.4 \pm 53.1$ minutes in the JW group, and $212.7 \pm 70.3$ minutes in the control group.

Intra-abdominal fluid collection was confirmed in one $\mathrm{pa}^{-}$ tient in the JW group, and in two patients in the control group. There was one case of intra-peritoneal haemorrhage, for which was reoperation was performed, in the control group. The mean duration of hospital stay was 7.76 days in the JW group, and 7.4 days in the transfusion group.

Iron supplements were postoperatively administered to one patient in the JW group, and blood transfusion was performed in four patients in the control group (5.3\%). Of the four pa- tients who received blood transfusions, two patients received it before surgery, one patient during surgery, and one after surgery.

\section{Postoperative haemoglobin and haematocrit change (Table 3, Fig. 1)}

The average preoperative haemoglobin level of the JW group was $13.1 \mathrm{~g} / \mathrm{dl}$, and $13.0 \mathrm{~g} / \mathrm{dl}$ on the first day after surgery, $11.4 \mathrm{~g} / \mathrm{dl}$ on the third day after surgery, and $11.4 \mathrm{~g} / \mathrm{dl}$ on the day of discharge. For the control group, it was $12.6 \mathrm{~g} / \mathrm{dl}$ before surgery and $12.7 \mathrm{~g} / \mathrm{dl}, 12.6 \mathrm{~g} / \mathrm{dl}, 11.1 \mathrm{~g} / \mathrm{dl}, 1$ day after surgery, 3 days after surgery, and at discharge, respectively. There was no statistically significant difference in the haemoglobin and haematocrit levels between the two groups.

\section{DISCUSSION}

In the last two decades, laparoscopic surgery has become the standard treatment for stage I gastric cancer. In the meantime, the need for blood transfusion has steadily declined, thanks to the development of techniques and equipment, and improvement in postoperative management. However, despite these advances, the rate of blood transfusion in laparoscopic gastrectomy including D1+ lymphadenectomy and above has been reported to be 6.7 to $19.7 \% .^{4-7}$ Thus surgical treatment of gastric cancer in patients, who refuse blood transfusion for

Table 2. Perioperative outcomes

\begin{tabular}{|c|c|c|c|}
\hline & Control $(n=75)$ & Jehovah's Witnesses $(n=25)$ & $p$ value \\
\hline Operation & & & 0.051 \\
\hline Distal & $67(89.3 \%)$ & $18(72 \%)$ & \\
\hline Total & $8(10.7 \%)$ & $7(28 \%)$ & \\
\hline Combined operation & $5(6.7 \%)$ & $1(4 \%)$ & 1.000 \\
\hline Intraoperative blood loss, ml & $179.73 \pm 163.8$ & $202.40 \pm 172.6$ & 0.556 \\
\hline Operation time, minutes & $212.7 \pm 70.3$ & $212.4 \pm 53.1$ & 0.983 \\
\hline Retrieved lymph node & $29.3 \pm 12.1$ & $27.8 \pm 13.9$ & 0.607 \\
\hline Pathologic stage & & & 0.341 \\
\hline I & $67(89.3 \%)$ & $25(100 \%)$ & \\
\hline$\|\& \mid\|$ & $8(10.7 \%)$ & $0(0 \%)$ & \\
\hline Complication & $3(4 \%)$ & $1(4 \%)$ & 1.000 \\
\hline Re-operation & $1(1.3 \%)$ & $0(0 \%)$ & 1.000 \\
\hline Hospital stay, days & $7.40 \pm 3.4$ & $7.76 \pm 2.6$ & 0.629 \\
\hline Transfusion & $4(5.3 \%)$ & $0(0 \%)$ & 0.569 \\
\hline IV Iron suppliment & $0(0 \%)$ & $1(4 \%)$ & 1.000 \\
\hline
\end{tabular}


Table 3. Postoperative hemoglobin and hematocrit change

\begin{tabular}{lccc} 
& $\begin{array}{c}\text { Control } \\
(\mathbf{n}=75)\end{array}$ & $\begin{array}{c}\text { Jehovah's } \\
\text { Witnesses }(\mathbf{n = 2 5})\end{array}$ & $p$ value \\
\hline $\begin{array}{l}\text { Hemoglobin, g/dl } \\
\text { Preoperative }\end{array}$ & $12.7 \pm 1.58$ & $13.1 \pm 1.55$ & 0.255 \\
Postoperative day 1 & $12.6 \pm 1.61$ & $13.0 \pm 1.40$ & 0.311 \\
Postoperative day 3 & $11.1 \pm 1.44$ & $11.4 \pm 1.28$ & 0.303 \\
On discharge & $12.6 \pm 10.4$ & $11.4 \pm 1.51$ & 0.674 \\
Hematocrit, \% & & & \\
Preoperative & $37.9 \pm 4.57$ & $39.4 \pm 3.94$ & 0.133 \\
Postoperative day 1 & $37.8 \pm 4.75$ & $39.1 \pm 3.67$ & 0.228 \\
Postoperative day 3 & $32.9 \pm 4.22$ & $33.9 \pm 4.08$ & 0.260 \\
On discharge & $33.1 \pm 3.86$ & $33.9 \pm 4.21$ & 0.377 \\
\hline
\end{tabular}

religious reasons, such as Jehovah's Witnesses, remains as a major challenge. Although our study is a retrospective study, to our knowledge, it is the first study to evaluate the safety of gastric surgery in Jehovah's Witnesses who refuse transfusions, and compare them to a control group.

In this study, 25 patients from Jehovah's Witnesses were underwent 1:3 matching for appropriate statistical power. As a result, there was a relatively well-matched result in terms of co-morbidities and ASA score, which reflect the clinical characteristics of the patient. There was no statistical significance between two groups; however, final pathology reported 8 patients with advanced gastric cancer in the control group but no patients with advanced gastric cancer in the JW group, which shows a slightly inappropriate distribution pattern. This is considered to be a selection bias, a typical limitation of retrospective analysis. In our institution, laparoscopic gastrectomy was performed in early gastric cancer patients from 2005. However, in Jehovah's Witnesses, open gastrectomy was performed according to the judgment of the surgeon until 2009 regardless of cancer stage. After the operator became accustomed to it, laparoscopic gastrectomy was performed on patients from Jehovah's Witnesses. This leads to the slightly inappropriate distribution between these two groups, since we applied more strict criteria to the JW group when we select preoperative patients.

In this study, blood transfusion was not performed before and after surgery for the JW group, but blood transfusion was performed in four patients $(5.3 \%, 4 / 75)$ in the control group. One of the two patients, who received a blood transfusion before surgery, had been admitted to our institution with the chief complaint of bloody stool, and had a haemoglobin level of $7.7 \mathrm{mg} / \mathrm{dl}$ at that time. This patient was transfused 2 pints

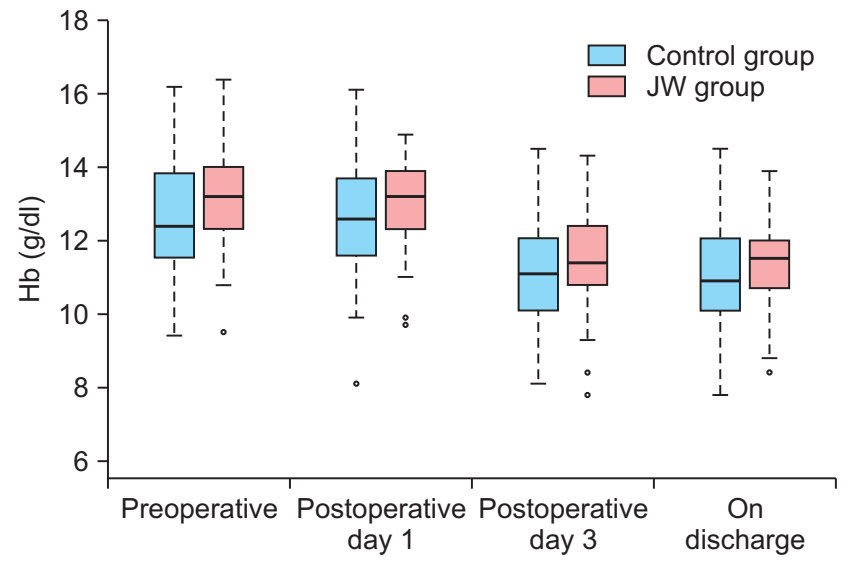

Fig. 1. Postoperative hemoglobin change.

of packed RBC. The other patient was transfused with 2 pints of packed RBC during the process of endoscopic haemostasis following endoscopic resection. One patient, who received a blood transfusion during surgery under the supervision of anaesthesiologist, was an 88-year-old woman, with a haemoglobin level of $9.4 \mathrm{mg} / \mathrm{dl}$ (preoperative Hb 10.9, estimated blood loss $50 \mathrm{cc}$ ) during the operation. Another patient, who received a blood transfusion after surgery, was on warfarin due to atrial fibrillation prior to surgery. On the 10th day after the operation and the 3rd day after starting medications, the patient's haemoglobin level was measured at $6.4 \mathrm{mg} / \mathrm{dl}$ with tachycardia. The patient was re-operated and blood transfusions were performed accordingly.

High-dose intravenous iron infusion has undergone the most remarkable development among methods of treatment for patients with preoperative and postoperative anaemia or bleeding. ${ }^{8}$ An IV-iron sucrose infusion is considered safe and effective in patients on dialysis ${ }^{9}$ and before orthopaedic surgery. ${ }^{10}$ In addition, the use of IV iron in patients with gastric cancer also has produced good results in terms of haemoglobin elevation. ${ }^{11,12}$ Use of high-dose iron supplements for treating preoperative anaemia holds clinical significance in operations that are performed according to a set schedule, such as gastric surgery. In this study, one patient in the JW group received an intravenous infusion of $500 \mathrm{mg}$ ferric carboxymaltose on the 3rd day after total gastrectomy. For this patient, ANH was performed during the operation, and the patient's haemoglobin level was $7.8 \mathrm{mg} / \mathrm{dl}$ at the time of infusion. A major reason for the limited use of IV iron infusion in this study is that the high-dose IV iron infusion was not available in Korea until late 2012, and clinicians lacked experience in using the same. A patient blood management system has been introduced at our institution, and is currently used for multiple purposes. Accordingly, high-dose IV iron infusion has been 
recommended as a primary method of treatment for preoperative anaemia at our institution.

Other well-known techniques for preserving blood components during surgery are acute normovolemic haemodilution (ANH) and cell salvage. In ANH, blood is collected following anaesthesia while the intravascular volume is maintained by using crystalloid and colloid fluids until resection of major lesions. This technique can reduce the loss of blood components during surgery and supplement blood components in emergency situations. Although the use of ANH in gastrointestinal surgery is still controversial, it is known to reduce the need for transfusion and the amount of blood transfused especially when massive blood loss is expected. ${ }^{13-15}$ In this study, ANH was performed on one patient in the JW group on the patient's request. She was a 72-year-old woman, and she had been scheduled for total gastrectomy and cholecystectomy for gastric cancer and gallstone disease. The preoperative $\mathrm{Hb}$ level was $12.2 \mathrm{mg} / \mathrm{dl}$. In the case of cell salvage, some of the patients who were Jehovah's Witnesses agreed to undergo cell salvage only if the cell salvage machine allowed blood to flow continuously, and did not store blood. However, the use of cell salvage in gastric cancer patients is not recommended because some claim that it may cause distant metastasis by cancer cells exposed during surgery. ${ }^{16}$

Jehovah's Witnesses are a religious group of close to 7 million people in 230 countries. They refuse blood transfusions due to their religious beliefs. In the past, medical communities considered their refusal to receive blood transfusions to be extreme, even to the point of considering it as suicidal behaviour. However, in recent years, such perception has changed. The development of medical technology over the past years has effectively reduced intraoperative haemorrhage and given rise to a variety of adjuvant therapies to reduced blood transfusion, such as pre-operative management and autologous blood transfusions. In line with these changes, non-blood transfusion treatment has been available to the general public to prevent the side effects of blood transfusion.

This study has the inherent limitations of retrospective analysis, i.e. includes a small number of patients, and deals with clinical situations in which no standard guidelines are available for patients with anaemia; however, this study is meaningful in the sense that the control group was relatively well-matched with the JW group.

In conclusion, the prospect of having to undergo major surgery can be challenging for Jehovah's Witnesses as well as for the clinicians treating them. However, laparoscopic gastrectomy without transfusion may be performed in these patients with an equivalent risk to that seen in the control group. Laparoscopic gastrectomy can be applied to Jehovah's Witnesses if the specialied cancer center has sufficient experience in stomach cancer surgery, even if there is not enough experience in bloodless surgery.

\section{ACKNOWLEDGMENTS}

This research was supported by the supported by the Soonchunhyang University Research Fund.

\section{REFERENCES}

1) Kitano S, Iso Y, Moriyama M, Sugimachi K. Laparoscopy-assisted Billroth I gastrectomy. Surg Laparosc Endosc 1994;4:146-148.

2) Kim W, Kim HH, Han SU, et al. Decreased Morbidity of Laparoscopic Distal Gastrectomy Compared With Open Distal Gastrectomy for Stage I Gastric Cancer: Short-term Outcomes From a Multicenter Randomized Controlled Trial (KLASS-01). Ann Surg 2016;263:28-35.

3) Hur H, Lee HY, Lee HJ, et al. Efficacy of laparoscopic subtotal gastrectomy with D2 lymphadenectomy for locally advanced gastric cancer: the protocol of the KLASS-02 multicenter randomized controlled clinical trial. BMC Cancer 2015;15:355.

4) Kim JJ, Song KY, Chin HM, et al. Totally laparoscopic gastrectomy with various types of intracorporeal anastomosis using laparoscopic linear staplers: preliminary experience. Surg Endosc 2008;22:436-442.

5) Ojima T, Iwahashi M, Nakamori M, et al. Association of allogeneic blood transfusions and long-term survival of patients with gastric cancer after curative gastrectomy. J Gastrointest Surg 2009;13:1821-1830.

6) Tu RH, Huang CM, Lin JX, et al. A scoring system to predict the risk of organ/space surgical site infections after laparoscopic gastrectomy for gastric cancer based on a large-scale retrospective study. Surg Endosc 2016;30:3026-3034.

7) Gui R, Tang H, Gao M, et al. Impact of perioperative blood transfusion on survival of patients undergoing laparoscopic gastrectomy for gastric cancer. J BUON 2017;22:396-402.

8) Goodnough LT, Shander A, Brecher ME. Transfusion medicine: looking to the future. Lancet 2003;361:161-169.

9) Charytan C, Levin N, Al-Saloum M, Hafeez T, Gagnon S, Van Wyck DB. Efficacy and safety of iron sucrose for iron deficiency in patients with dialysis-associated anemia: North American clinical trial. Am J Kidney Dis 2001;37:300-307.

10) Theusinger OM, Leyvraz PF, Schanz U, Seifert B, Spahn DR. Treatment of iron deficiency anemia in orthopedic surgery with intravenous iron: efficacy and limits: a prospective study. Anesthesiology 2007; 107:923-927.

11) Yoon HM, Kim YW, Nam BH, et al. Intravenous iron supplementation may be superior to observation in acute isovolemic anemia after gastrectomy for cancer. World J Gastroenterol 2014;20:18521857. 
12) Kim YW, Bae JM, Park YK, et al. Effect of Intravenous Ferric Carboxymaltose on Hemoglobin Response Among Patients With Acute Isovolemic Anemia Following Gastrectomy: The FAIRY Randomized Clinical Trial. JAMA 2017;317:2097-2104.

13) Sanders G, Mellor N, Rickards K, et al. Prospective randomized controlled trial of acute normovolaemic haemodilution in major gastrointestinal surgery. Br J Anaesth 2004;93:775-781.

14) Tomimaru Y, Noguchi K, Dono K. Necessity for autologous blood storage and transfusion in patients undergoing pancreatoduodenectomy. Surg Today 2017;47:568-574.

15) Jeon YB, Yun S, Ok SY, Kim HJ, Choi D. Impact of a Transfusion-free Program on Patients Undergoing Pancreaticoduodenectomy. Am Surg 2016;82:140-145.

16) Kuppurao L, Wee M. Perioperative cell salvage. Contin Educ Anaesth Crit Care Pain 2010;10:104-108. 